\title{
Does COPD differ by veteran status in males $50-79$ years of age?
}

\author{
Kole P Knutson, Jordan M Stellato, Kelli R Vogler, Jourdan B Whorley, Vic Holmes and Jessica L Hartos* \\ Department of Physician Assistant Studies, University of North Texas Health Science Center, USA
}

\begin{abstract}
Purpose: With little research addressing veteran status as related to COPD, the purpose of this study is to assess whether COPD differs by veteran status in males ages 50-79 in the general population.

Methods: This study was a cross sectional analysis using 2016 BRFSS data for males ages 50-79 in Arkansas (N=1283), Montana (N=1586), New Jersey (N=1842), Tennessee $(\mathrm{N}=1473)$, and West Virginia $(\mathrm{N}=1854)$. Multiple logistic regression analyses were performed by state to determine whether COPD status differed by veteran status when controlling for age, ethnicity, tobacco use, weight status, general health, asthma, income, education, and employment.

Results: Across states, less than one-fifth of participants reported COPD (9-18\%), and 25-40\% reported veteran status. After controlling for socioeconomic, demographic, and health factors, results showed significant consistent relationships between COPD and veteran status in three out of five states. COPD was also consistently related to tobacco use, general health, and having ever been diagnosed with asthma in all 5 states.

Conclusion: The results of this study indicated that veteran males ages 50-79 are about two times more likely to have COPD when compared to non-veteran males of the same age in the general population. Due to the low prevalence of COPD overall, it is recommended that health care providers screen for COPD in this target population when patients present with symptoms, especially for current or ex-military personnel. In addition, COPD was highly related to smoking, general health, and asthma. Providers should identify and treat COPD and any other health conditions concurrently to make sure they are managed properly. Most importantly, as COPD is a disease of chronicity, providers should educate and refer smokers as early as possible for assistance with smoking cessation.
\end{abstract}

\section{Introduction}

Chronic Obstructive Pulmonary Disease (COPD) is defined as a progressive respiratory disease characterized by chronic airflow impedance [1-4]. COPD is not typically diagnosed until after lung function has already been nearly compromised [3] and it has been reported that an additional twelve million individuals are thought to be undiagnosed [5]. Past studies report that COPD could actually affect up to $16.8 \%$ of the population $[4,6,7]$, and is a leading cause of death $[2,3,8,9]$. Additionally, several medical conditions have been reported as having a significant relationship with COPD including cardiovascular disease, ischemic heart disease, lung cancer, asthma, obesity, hypertension, diabetes, depression, anxiety, and obstructive sleep apnea $[1,2,4,10,11]$.

Research has repeatedly indicated that COPD is highly related to tobacco use. Studies report that up to $90 \%$ of COPD patients identify as current or former smokers $[1,2,4,5,9,12,13]$. In addition, COPD patients are more likely to be white males $[6-8,9,12]$ and have lower levels of income $[7,12]$ and education $[7,10]$.

COPD may also be related to veteran status. Several studies have determined the prevalence of COPD separately among the general population [6,12] and veteran population [13-16], but there is a lack of research comparing COPD status and veteran status $[11,16]$. One study, however, conducted at the Cincinnati Veterans Administration (VA) found that veterans had a higher rate of COPD when compared to the U.S. general population [16]. Furthermore, research has not adequately accounted for any age or gender differences in COPD status between these populations. Therefore, the purpose of this study was to assess whether COPD status differs by veteran status in males ages 50-79.

\section{Methods}

\section{Design}

This cross-sectional analysis used 2016 data from the Behavioral Risk Factor Surveillance System (BRFSS) conducted by the Center for Disease Control and Prevention (CDC) [17]. BRFSS collects healthrelated data annually through telephone interviews with adults in all fifty states, the District of Columbia, and three U.S. territories using random digit dialing techniques. The CDC compiles all BRFSS data and makes de-identified data available to researchers for secondary data analysis. This study was given exempt status by Institutional Review Board of The University of North Texas Health Science Center.

\section{Sample}

The samples for this study included males ages 50-79 from Arkansas $(\mathrm{N}=1,283)$, Montana $(\mathrm{N}=1,586)$, New Jersey $(\mathrm{N}=1,842)$, Tennessee $(\mathrm{N}=1,473)$, and West Virginia $(\mathrm{N}=1,854)$ with data for COPD. These states were chosen because they have a higher prevalence of veterans and reported COPD diagnosis when compared to other U.S. states [18].

${ }^{\star}$ Correspondence to: Jessica L Hartos, Department of Physician Assistant Studies, University of North Texas Health Science Center, 3500 Camp Bowie Blvd, Fort Worth, Texas, 76107, USA, Tel: (817) 735-2454, Fax: (817) 7352529, E-mail: Jessica.hartos@unthsc.edu

Key words: veteran, COPD, smoking, male, adults, general population

Received: June 05, 2018; Accepted: June 22, 2018; Published: June 25, 2018 


\section{Data}

The outcome, COPD status, was measured as ever/never diagnosed with "chronic obstructive pulmonary disease, chronic bronchitis, and/ or emphysema" in the participant's lifetime. The factor of interest, veteran status, was measured as ever/never on active duty in the armed forces including "regular, Guard, and Reserve."

The control variables included age, ethnicity/race, smoker status, BMI, general health, asthma, income level, education level, and employment status. Age was dichotomized as "50-64 years of age" versus "65-79 years of age." Since the majority of the participants reported their ethnicity as White, ethnicity/race was dichotomized as "white, non-Hispanic" versus "other." Smoker status was categorized as "never smoker," "former smoker," and "current smoker." BMI was dichotomized as "overweight or obese" versus "not overweight or obese." In BRFSS, general health is defined as "poor health," fair health," "good health," "very good health," and "excellent health"; however, due to low frequencies of participants with very good health and excellent health, four categories were used: "poor health," "fair health," "good health," and "very good/excellent health." Asthma was measured as ever/never being diagnosed with asthma. Income level was measured as an annual income of " $\$ 0$ to less than $\$ 25,000$," " $\$ 25,000$ to less than $\$ 50,000$," and " $\$ 50,000$ or more." Education level was measured as yes/ no graduated from college or technical school. Employment status was categorized as "wages/self-employed," "retired," or "other."

\section{Analysis}

Frequency distributions were used to describe the sample as well as to assess any issues with the distributions of variables. Multiple logistic regression analysis was used to assess the relationship between COPD status and veteran status while controlling for demographic, health, and socioeconomic factors. All analyses were conducted separately by state (instead of combining the data) to determine patterns in variable relations across similar samples. A similar finding in 3 or more out of 5 states was considered reliable evidence for a relationship. Any observations with missing data for any variables were excluded from the adjusted analysis. All analyses were conducted in STATA 15 (Copyright 1985-2017, StataCorp LLC).

\section{Results}

\section{Descriptive statistics}

Table 1 lists participant characteristics for males ages 50-79 in Arkansas, Montana, New Jersey, Tennessee, and West Virginia. Less than one-fifth of the participants reported ever being diagnosed with COPD (9-18\%) and at least one fourth of the participants identified as veterans (25-40\%). For demographic factors, approximately half of the participants were 50-64 years of age (42-56\%) and most identified as white, non-Hispanic (74-94\%). For health concerns, less than one-fifth reporting smoking (13-21\%); the majority reported being overweight or obese (63-81\%); over one-third reported very good/excellent health (35-49\%); and few reported having been diagnosed with asthma (8$14 \%)$. For socioeconomic status, less than one-third of the participants reported an income of $\$ 0$ to less than $\$ 25,000$ per year (19-30\%) or $\$ 25,000$ to less than $\$ 50,000$ per year (19-30\%); the majority reported that they did not graduate college/technical school (54-72\%); and about half reported working for wages or being self-employed (37-51\%).

\section{Adjusted statistics}

As shown in Table 2, the results of multiple logistic regression analyses for males ages 50-79 indicated that after controlling for all other variables in the model, COPD status were significantly related to veteran status in 3 out of 5 states. Veterans were about 2 times more likely to report COPD than non-veterans. In addition, former smokers were about 3 times more likely, and current smokers were about 4.5 times more likely, to report COPD compared never-smokers in all five states. Also, those with asthma were about 4.5 times more likely to report COPD compared to those without asthma in all 5 states. In contrast, compared to those with poor health, those who reported fair, good, or very good/excellent health were about 2 to 11 times less likely to report COPD across states.

\section{Discussion}

The purpose of this study was to assess whether COPD status differed by veteran status in males ages 50-79 in the general population when controlling for demographic, health, and socioeconomic factors that may be related to COPD. Across states, less than one-fifth of participants reported ever being diagnosed with COPD, and at least one-fourth reported being a veteran. The results of adjusted analyses revealed that COPD status was significantly related to veteran status across states. These results are consistent with a study indicating that veterans may have higher rates of COPD than the general population [16]. In addition, our study found that being a former or current smoker was also significantly related to COPD status across all states, which is similar to many other studies that have reported strong relations between smoking and COPD $[1,2,4,5,9,12,13]$. Furthermore, our study supports the findings of other studies that indicate that fair or better health is inversely related to COPD $[11,12]$ and asthma is highly related to COPD [7].

Smoking may contribute to the relationship between COPD and veteran status [19]. According to the CDC [20] veteran males have a higher prevalence of smoking than non-veteran males. However, even after controlling for smoking, veteran status still had a significant relationship with COPD. This would suggest that although smoking is related to COPD and veterans may smoke more than civilians, other factors related to veteran status contribute to COPD. Indeed, another study comparing COPD in different occupations found that serving in the armed forces was related to higher COPD rates than other occupations [14]. One such related factor may be higher exposure to hazardous agents in the military versus other occupations [14,19]. Future studies may want to include data for hazardous exposures that could contribute to veteran and non-veteran COPD status. Knowing whether or not people with COPD were exposed and/or continue to be exposed to hazardous agents could help practitioners screen earlier, modify treatment plans, and educate about reducing such exposures.

\section{Limitations}

Using BRFFS data allowed us to use state data most relevant to our clinical question. The large sample sizes allowed us to analyze the data based on the age and gender of our target population. However, our study findings may be limited by not having data for the severity of COPD, treatment modalities being used, or compliance with treatment plans [21]. Future studies should include such information. In addition, COPD rates in this study may be underreported given that millions of individuals in the US population may have COPD but no formal diagnosis [5]. Future studies may define COPD status by symptoms rather than diagnosis in order to incorporate patients living with undiagnosed COPD. 
Table 1. Participant Characteristics by State

\begin{tabular}{|c|c|c|c|c|c|c|c|c|c|c|}
\hline \multirow[t]{2}{*}{ Variable } & \multicolumn{2}{|c|}{$\begin{array}{c}\text { Arkansas } \\
\mathrm{N}=1283\end{array}$} & \multicolumn{2}{|c|}{$\begin{array}{l}\text { Montana } \\
\mathrm{N}=1586\end{array}$} & \multicolumn{2}{|c|}{$\begin{array}{c}\text { New Jersey } \\
\mathbf{N}=\mathbf{1 8 4 2}\end{array}$} & \multicolumn{2}{|c|}{$\begin{array}{l}\text { Tennessee } \\
\mathrm{N}=1473\end{array}$} & \multicolumn{2}{|c|}{$\begin{array}{c}\text { West Virginia } \\
\mathbf{N}=\mathbf{1 8 5 4}\end{array}$} \\
\hline & $\mathbf{N}$ & $\%$ & $\mathbf{N}$ & $\%$ & $\mathbf{N}$ & $\%$ & $\mathbf{N}$ & $\%$ & $\mathbf{N}$ & $\%$ \\
\hline COPD diagnosis & 1274 & 99 & 1576 & 99 & 1842 & 100 & 1464 & 99 & 1842 & 99 \\
\hline Yes & 166 & 13 & 151 & 10 & 171 & 9 & 166 & 11 & 324 & 18 \\
\hline No & 1108 & 87 & 1425 & 90 & 1671 & 91 & 1300 & 88 & 1518 & 82 \\
\hline Veteran status & 1274 & 99 & 1576 & 99 & 1841 & 100 & 1464 & 100 & 1854 & 100 \\
\hline Yes & 516 & 40 & 590 & 37 & 452 & 25 & 533 & 36 & 615 & 33 \\
\hline No & 766 & 60 & 988 & 63 & 1389 & 75 & 935 & 64 & 1239 & 67 \\
\hline Age & 1283 & 100 & 1586 & 100 & 1842 & 100 & 1473 & 100 & 1854 & 100 \\
\hline $50-64$ & 612 & 48 & 848 & 53 & 774 & 42 & 820 & 56 & 1047 & 56 \\
\hline $65-79$ & 671 & 52 & 738 & 47 & 1068 & 58 & 653 & 44 & 807 & 44 \\
\hline Ethnicity & 1266 & 99 & 1561 & 98 & 1778 & 97 & 1440 & 98 & 1825 & 98 \\
\hline White, non-Hispanic & 1019 & 80 & 1354 & 87 & 1391 & 78 & 1217 & 84 & 1,23 & 94 \\
\hline Other & 247 & 20 & 207 & 13 & 387 & 22 & 234 & 16 & 106 & 6 \\
\hline Tobacco use & 1241 & 97 & 1552 & 98 & 1782 & 97 & 1420 & 96 & 1814 & 98 \\
\hline Never smoked & 502 & 41 & 683 & 44 & 873 & 49 & 577 & 41 & 704 & 39 \\
\hline Former smoker & 511 & 41 & 632 & 41 & 656 & 37 & 564 & 40 & 735 & 41 \\
\hline Current smoker & 228 & 19 & 237 & 16 & 253 & 14 & 279 & 20 & 375 & 21 \\
\hline Weight status & 957 & 75 & 1199 & 76 & 1754 & 95 & 1099 & 75 & 1455 & 78 \\
\hline Overweight or obese & 957 & 77 & 1199 & 78 & 1373 & 78 & 1099 & 77 & 1455 & 81 \\
\hline Not overweight or obese & 278 & 23 & 344 & 22 & 381 & 22 & 325 & 23 & 338 & 19 \\
\hline General Health & 1280 & 100 & 1581 & 100 & 1835 & 100 & 1471 & 100 & 1846 & 100 \\
\hline Poor & 140 & 11 & 110 & 7 & 92 & 5 & 144 & 10 & 221 & 12 \\
\hline Fair & 250 & 20 & 255 & 16 & 266 & 15 & 263 & 18 & 380 & 21 \\
\hline Good & 446 & 35 & 497 & 31 & 584 & 32 & 500 & 34 & 600 & 33 \\
\hline Very good/excellent & 444 & 35 & 719 & 45 & 893 & 49 & 564 & 38 & 645 & 35 \\
\hline Asthma & 1282 & 100 & 1580 & 100 & 1837 & 100 & 1466 & 100 & 1846 & 100 \\
\hline Ever diagnosed & 126 & 10 & 163 & 10 & 150 & 8 & 166 & 11 & 211 & 11 \\
\hline Never diagnosed & 1156 & 90 & 1417 & 90 & 1687 & 92 & 1300 & 89 & 1635 & 89 \\
\hline Income & 1084 & 84 & 1391 & 88 & 1555 & 84 & 1255 & 85 & 1554 & 84 \\
\hline$\$ 0$ to less than $\$ 25,000$ & 294 & 27 & 348 & 25 & 293 & 19 & 353 & 28 & 469 & 30 \\
\hline$\$ 25,000$ to less than $\$ 50,000$ & 274 & 25 & 403 & 29 & 289 & 19 & 360 & 29 & 460 & 30 \\
\hline$\$ 50,000$ or more & 516 & 48 & 640 & 46 & 973 & 63 & 542 & 43 & 625 & 40 \\
\hline Education & 1278 & 100 & 1581 & 100 & 1833 & 100 & 1469 & 100 & 1850 & 100 \\
\hline Graduated college/technical school & 455 & 36 & 543 & 34 & 851 & 46 & 477 & 32 & 521 & 28 \\
\hline Did not graduate college/technical school & 823 & 64 & 1038 & 66 & 982 & 54 & 992 & 68 & 1329 & 72 \\
\hline Employment & 1281 & 100 & 1574 & 99 & 1823 & 99 & 1462 & 99 & 1851 & 100 \\
\hline Wages/self-employed & 469 & 37 & 802 & 51 & 917 & 50 & 637 & 44 & 688 & 37 \\
\hline Other & 226 & 18 & 172 & 11 & 254 & 14 & 259 & 18 & 388 & 21 \\
\hline Retired & 586 & 46 & 600 & 38 & 652 & 36 & 566 & 39 & 775 & 42 \\
\hline
\end{tabular}

Table 2. Adjusted Results by State

\begin{tabular}{|c|c|c|c|c|c|c|c|c|c|c|c|c|c|c|c|}
\hline \multirow{3}{*}{$\begin{array}{c}\text { Predicting COPD } \\
\text { (diagnosis vs. no } \\
\text { diagnosis) }\end{array}$} & \multicolumn{3}{|c|}{ Arkansas } & \multicolumn{3}{|c|}{ Montana } & \multicolumn{3}{|c|}{ New Jersey } & \multicolumn{3}{|c|}{ Tennessee } & \multicolumn{3}{|c|}{ West Virginia } \\
\hline & \multirow{2}{*}{ AOR } & \multicolumn{2}{|c|}{$95 \%$ CI } & \multirow{2}{*}{ AOR } & \multicolumn{2}{|c|}{$95 \%$ CI } & \multirow{2}{*}{ AOR } & \multicolumn{2}{|c|}{$95 \%$ CI } & \multirow{2}{*}{ AOR } & \multicolumn{2}{|c|}{$95 \%$ CI } & \multirow{2}{*}{ AOR } & \multicolumn{2}{|c|}{$95 \%$ CI } \\
\hline & & Low & High & & Low & High & & Low & High & & Low & High & & Low & High \\
\hline \multicolumn{16}{|l|}{ Veteran Status } \\
\hline Non-veteran & ref & - & - & ref & - & - & ref & - & - & ref & - & - & ref & - & - \\
\hline Veteran & 1.88 & 1.21 & 2.95 & 2.38 & 1.48 & 3.81 & 2.01 & 1.23 & 3.17 & 1.31 & 0.86 & 1.99 & 0.94 & 0.66 & 1.33 \\
\hline \multicolumn{16}{|l|}{ Age } \\
\hline $50-64$ & ref & - & - & ref & - & - & ref & - & - & ref & - & - & ref & - & - \\
\hline $65-79$ & 0.87 & 0.75 & 2.26 & 1.45 & 0.83 & 2.54 & 0.94 & 0.55 & 1.61 & 0.98 & 0.6 & 1.61 & 0.59 & 0.39 & 0.91 \\
\hline \multicolumn{16}{|l|}{ Ethnicity } \\
\hline Other & ref & - & - & ref & - & - & ref & - & - & ref & - & - & ref & - & - \\
\hline White, non-Hispanic & 1.31 & 0.75 & 2.26 & 2.19 & 1.17 & 4.13 & 2.02 & 1.18 & 3.47 & 1.43 & 0.84 & 2.43 & 0.46 & 0.25 & 0.84 \\
\hline \multicolumn{16}{|l|}{ Tobacco Use } \\
\hline Never & ref & - & - & ref & - & - & ref & - & - & ref & - & - & ref & - & - \\
\hline Former & 2.86 & 1.62 & 5.06 & 3.94 & 2.14 & 7.26 & 2.75 & 1.63 & 4.63 & 2.76 & 1.57 & 4.85 & 2.83 & 1.82 & 4.34 \\
\hline Current & 4.59 & 2.43 & 8.68 & 6.37 & 3.19 & 12.71 & 4.35 & 2.43 & 7.78 & 5.34 & 2.93 & 9.75 & 5.54 & 3.45 & 8.88 \\
\hline Weight Status & & & & & & & & & & & & & & & \\
\hline
\end{tabular}




\begin{tabular}{|c|c|c|c|c|c|c|c|c|c|c|c|c|c|c|c|}
\hline Not overweight or obese & ref & - & - & ref & - & - & ref & - & - & ref & - & - & ref & - & - \\
\hline Overweight or obese & 1.29 & 0.8 & 2.1 & 1.02 & 0.6 & 1.72 & 1.23 & 0.75 & 2.02 & 1.07 & 0.67 & 1.7 & 1.17 & 0.79 & 1.74 \\
\hline \multicolumn{16}{|l|}{ General Health } \\
\hline Poor & ref & - & - & ref & - & - & ref & - & - & ref & - & - & ref & - & - \\
\hline Fair & 0.37 & 0.2 & 0.66 & 0.5 & 0.26 & 0.96 & 0.78 & 0.41 & 1.48 & 0.53 & 0.3 & 0.95 & 0.72 & 0.46 & 1.12 \\
\hline Good & 0.17 & 0.09 & 0.32 & 0.32 & 0.17 & 0.63 & 0.22 & 0.11 & 0.43 & 0.35 & 0.2 & 0.63 & 0.29 & 0.18 & 0.47 \\
\hline Very good/excellent & 0.09 & 0.04 & 0.19 & 0.15 & 0.07 & 0.31 & 0.14 & 0.07 & 0.28 & 0.18 & 0.09 & 0.38 & 0.1 & 0.06 & 0.19 \\
\hline \multicolumn{16}{|l|}{ Asthma } \\
\hline Never diagnosed & ref & - & - & ref & - & - & ref & - & - & ref & - & - & ref & - & - \\
\hline Ever diagnosed & 4.62 & 2.67 & 7.99 & 8.74 & 5.22 & 14.63 & 9.78 & 5.86 & 16.32 & 4.72 & 2.92 & 7.61 & 4.85 & 3.21 & 7.33 \\
\hline \multicolumn{16}{|l|}{ Income } \\
\hline$\$ 0$ to less than $\$ 25,000$ & ref & - & - & ref & - & - & ref & - & - & ref & - & - & ref & - & - \\
\hline $\begin{array}{l}\$ 25,000 \text { to less than } \\
\$ 50,000\end{array}$ & 1.03 & 0.6 & 1.78 & 0.51 & 0.29 & 0.89 & 0.52 & 0.29 & 0.94 & 0.72 & 0.44 & 1.17 & 1.03 & 0.68 & 1.54 \\
\hline$\$ 50,000+$ & 0.75 & 0.41 & 1.35 & 0.69 & 0.38 & 1.24 & 0.61 & 0.35 & 1.07 & 0.63 & 0.35 & 1.13 & 0.82 & 0.51 & 1.33 \\
\hline \multicolumn{16}{|l|}{ Education } \\
\hline $\begin{array}{l}\text { Did not graduate college/ } \\
\text { tech school }\end{array}$ & ref & - & - & ref & - & - & ref & - & - & ref & - & - & ref & - & - \\
\hline $\begin{array}{l}\text { Graduated college/tech } \\
\text { school }\end{array}$ & 1.05 & 0.62 & 1.77 & 0.99 & 0.6 & 1.65 & 0.53 & 0.32 & 0.88 & 0.95 & 0.55 & 1.64 & 0.76 & 0.48 & 1.19 \\
\hline \multicolumn{16}{|l|}{ Employment } \\
\hline Wages/self-employed & ref & - & - & ref & - & - & ref & - & - & ref & - & - & ref & - & - \\
\hline Other & 1.27 & 0.63 & 2.58 & 2.15 & 1.1 & 4.18 & 1.13 & 0.60 & 2.12 & 3.52 & 1.87 & 6.63 & 1.4 & 0.85 & 2.32 \\
\hline Retired & 1.51 & 0.82 & 2.78 & 2.01 & 1.1 & 3.67 & 1.38 & 0.78 & 2.42 & 2.45 & 1.32 & 4.56 & 1.27 & 0.79 & 2.04 \\
\hline
\end{tabular}

\section{Conclusion}

Because this is a population-based study, the results may generalize to men between the ages of 50-79 in primary care settings. Different results may be found in the Veteran Administration or pulmonology settings. Primary care providers may expect less than one-fourth of their patients in this target population to have a COPD diagnosis, with higher prevalence related to (a) undiagnosed persons and (b) current or former military. Health care providers should screen for COPD if patients in this target population present with symptoms of COPD such as chronic cough, shortness of breath, fatigue, wheezing, and/ or frequent respiratory infections, with particular consideration for veterans. Primary care providers should work closely with pulmonology specialists in treatment plans for COPD. In addition, because there is a moderate prevalence of smokers within the target population and there is a high relation between smoking and COPD, providers should screen for both when patients present with symptoms of either. Providers should encourage, and provide resources for, tobacco cessation to reduce severity or complications for COPD or other health issues related to smoking. Lastly, because few patients in this target population have asthma, but asthma and COPD are highly related, providers should screen for both when patients present with symptoms of either. Providers should determine whether the patient's asthma is properly managed or if better management strategies or referrals are needed.

\section{References}

1. Mikkelsen RL, Middelboe T, Pisinger C, Stage KB (2004) Anxiety and depression is patients with chronic obstructive pulmonary disease (COPD). A review. Nordic $J$ Psychiatry 58: 65-70. [Crossref]

2. Owens RL, Macrea MM, Teodorescu M (2017) The overlaps of asthma or COPD with OSA: A focused review. Respirology 22: 1073-1083. [Crossref]

3. Sogbetum F, Eschenbacher WL, Welge JA, Panos RJ (2016) A comparison of five surveys that identify individuals at risk for airflow obstruction and chronic obstructive pulmonary disease. Respir Med 120: 1-9. [Crossref]

4. Viegi G, Pistelli F, Sherrill DL, Maio S, Baldacci S, et al. (2007) Definition, epidemiology and natural history of COPD. Eur Respir J 30: 993-1013. [Crossref]
5. National Institutes of Health (2010) Chronic Obstructive Pulmonary Disease (COPD). https://report.nih.gov/nihfactsheets/viewfactsheet.aspx?csid=77.

6. Ford ES, Croft JB, Mannino DM, Wheaton AG, Zhang X, et al. (2013) COPD surveillance--United States, 1999-2011. Chest 144: 284-305. [Crossref]

7. Kim J, Kim YS, Kim K, Oh YM, Yoo KH, et al. (2017) Socioeconomic impact of asthma, chronic obstructive pulmonary disease and asthma-COPD overlap syndrome. $J$ Thorac Dis 9: 1547-1556. [Crossref]

8. Centers for Disease Control and Prevention (2017) FastStats - Leading Causes of Death.

9. Halbert RJ, Natoli JL, Gano A, Badamgarav E, Buist AS, et al. (2006) Global burden of COPD: systematic review and meta-analysis. Eur Respir J 28: 523-532. [Crossref]

10. Centers for Disease Control and Prevention (2017) Chronic Obstructive Pulmonary Disease (COPD).

11. Mapel DW, Dedrick D, Davis K (2005) Trends and cardiovascular co-morbidities of COPD patients in the Veterans Administration medical system, 1991-1999. COPD 2: 35-41. [Crossref]

12. Allen-Ramey FC, Gupta S, DiBonaventura (2012) Patient characteristics, treatment patterns, and health outcomes among COPD phenotypes. Int J Chron Obstruct Pulmon Dis 7: 779-787. [Crossref]

13. Thompson WH, St-Hilaire S (2010) Prevalence of chronic obstructive pulmonary disease and tobacco use in veterans at Boise Veterans Affairs Medical Center. Respir Care 55: 555-560. [Crossref]

14. Hnizdo E, Sullivan PA, Bang KM, Wagner G (2002) Association between chronic obstructive pulmonary disease and employment by industry and occupation in the US population: A study of data from the third national health and nutrition examination survey. Am J Epidemiol 156: 738-746. [Crossref]

15. Lam TH, He Y, Shi QL, Huang JY, Zhang F, et al. (2002) Smoking, quitting, and mortality in a Chinese cohort of retired men. Ann Epidemiol 12: 316-320. [Crossref]

16. Murphy DE, Chaudhry Z, Almoosa KF, Panos RJ (2011) High prevalence of chronic obstructive pulmonary disease among veterans in the urban Midwest. Mil Med 176: 552-560. [Crossref]

17. Centers for Disease Control and Prevention (CDC). (2014) About BRFSS.

18. Centers for Disease Control \& Prevention (CDC). (2016). BRFSS Prevalence \& Trends Data.

19. Basaza R, Otieno E, Musinguzi A, Mugyenyi P, Haddock CK (2017) Factors influencing cigarette smoking among soldiers and costs of soldier smoking in the work place at Kakiri Barracks, Uganda. Tobacco Control 26: 330-333. 
20. Centers for Disease Control and Prevention (2012) Quick Stats: Current Smoking among Men Aged 25-64 Years, by Age Group and Veteran Status- National Health Interview Survey (NHIS), United States, 2007-2010. Morbidity and Mortality Weekly Report 61(45): 909-927. https://www.cdc.gov/mmwr/preview/mmwrhtml/mm6145a9.htm
21. Neugaard BI, Priest JL, Burch SP, Cantrell RC, Foulis PR (2011) Quality of care for veterans with chronic diseases: Performance on quality indicators, medication use and adherence, and health care utilization. Popul Health Manag 14: 99-106. [Crossref]

Copyright: (C2018 Knutson KP. This is an open-access article distributed under the terms of the Creative Commons Attribution License, which permits unrestricted use, distribution, and reproduction in any medium, provided the original author and source are credited. 